\title{
Congenital nystagmus in two infants born from mothers exposed to methadone during pregnancy
}

\author{
Francesca Tinelli ${ }^{1 *}$, Alessandra Gamucci ${ }^{1}$, Roberta Battini ${ }^{1}$ and Giovanni Cioni ${ }^{1,2}$
}

\begin{abstract}
Background: Methadone is commonly prescribed as a substitute for illicit opioids. Use of methadone during pregnancy is associated with neonatal abstinence syndrome (NAS), reduced head circumference as well as a slight increase in neonatal mortality and morbidity. Less is known about the effects of methadone on the visual system.

Cases: We report two Italian cases of nystagmus in infants born from mothers exposed to methadone during pregnancy. Ophthalmic or central disorders were excluded as a cause of nystagmus in both infants. The first case was followed at 3, 6 and 12 months while the second one was evaluated at 5 and 8 months. Both infants had normal neurological and cognitive development. Their first evaluation revealed different characteristics but both showed progressive improvement in ocular disorder, persistence of pendular horizontal nystagmus and nearly normal visual acuity.

Conclusion: This report, the first description of Italian cases of nystagmus related to use of methadone during pregnancy, underlies the importance of a careful investigation of drug use in pregnancy in cases of unexplained congenital nystagmus.
\end{abstract}

Keywords: Congenital nystagmus, Methadone, Pregnancy

\section{Background}

Methadone is commonly prescribed as a substitute for illicit opioids. It is a synthetic opioid which selectively binds to the $\mu$-opioid receptor, exerting a morphine-like effect [1]. Use of methadone during pregnancy is associated with reduced head circumference $[2,3]$ as well as slight increases in neonatal mortality [4-6] and morbidity and often neonatal abstinence syndrome (NAS) [7-9]. Less is known about the effects of methadone on visual system. Only a few studies [10-14] have been published on this topic which evidenced reduced acuity, nystagmus, delayed visual maturation and eye movement disorders in children born from mothers exposed to methadone during pregnancy, even if fundus examination was normal. Recently Cornish et al. [15] published a study on the short and long term effects on the visual system of children exposed to maternal drug misuse in utero. They reported

\footnotetext{
* Correspondence: francesca.tinelli@inpe.unipi.it

'Department of Developmental Neuroscience, IRCCS Fondazione Stella Maris, Via dei Giacinti 2, Calambrone, Pisa 56128, Italy

Full list of author information is available at the end of the article
}

not only a statistically significantly higher prevalence of strabismus and nystagmus in these children but also that these abnormalities tend to persist at 5 years of age and are associated with long-term visual morbidity, such as lack of binocularity and poor visual acuity. The results of a study [16] on VEPs in maternal drug-exposed infants indicate that exposure in utero to prescribed substitute methadone is independently associated with altered Flash VEPs at least in the neonatal period. Howewer, major interest has been focused on nystagmus and the underlying mechanisms that are still uncertain. Reported studies have some limitations: i) they are based on a retrospective design [12-14], therefore including only subjects who have developed visual disorders and ii) there are difficulties in enrolling subjects whose mothers used only methadone and no other substances during pregnancy. Recently, it has been reported that, among a cohort of methadoneexposed children referred to a paediatric visual electrophysiology service because of known visual problems, 92\% of infants who received pharmacological treatment for NAS developed nystagmus, while it was observable only 
in $38 \%$ of the infants who did not show a NAS severe enough [12].

Two possible mechanisms could account for the role of methadone in eliciting nystagmus. The most probable is the role of methadone (up-regulation) on $\mu$ - (opioid)receptors that are present at the cerebellum level and in high concentrations in the thalamus, prefrontal and cingulated cortex, basal ganglia and midbrain structures, all involved in ocular movement control. An alternative explanation is linked to abnormal $\mu$-opioid receptor binding in the developing brain-stem. Horizontal gaze steadiness is governed by a neural integrator that depends heavily on the nucleus prepositus hypoglossi and medial vestibular nucleus [17] where $\mu$-opioid receptors are located [18] and activated by opiates and methadone. Intracellular recordings from medial vestibular nucleus cells in rats have shown that an activation of these receptors induced an inhibition of the tonic discharge of these cells [19] and such inhibition may cause a vertical tonus imbalance with a vertical upward drift typical of downbeat nystagmus.

To summarize the percentage of nystagmus is very high among infants with NAS who were treated, but rather uncommon although possible in untreated NAS infants. In the two cases described in this report (one with NAS and one without NAS) nystagmus gradually improved, and so did visual acuity.

\section{Cases presentation}

Here we report two Italian cases of nystagmus in infants born from mothers exposed to methadone during pregnancy observed in the Vision Laboratory of IRCCS Fondazione Stella Maris in Pisa.

\section{Case 1}

A second pregnancy female infant born at 33 weeks gestational age (she has a 5 year-old sister in good health). The mother was administered methadone (dosage $30 \mathrm{mg} / \mathrm{d}$ ) during the entire pregnancy and denied use of other types of drugs except for diazepam. She used opiates, cannabinoids and cocaine till 7 years before. During all the pregnancy maternal urine samples were collected once a week and analyzed for methadone, opiate, benzodiazepines, amphetamines, cannabinoids and cocaine metabolites and were always in the normal range. The mother reported in the history that she did not use alcohol nor smoked. At birth NAS was not present. At 2 months the mother observed strange horizontal ocular movements and thought her daughter was blind. An ophthalmologic evaluation was performed and the fundus resulted normal. Cranial ultrasound revealed no abnormalities.

\section{3 months}

The infant showed significant pendular horizontal nystagmus with no null position. She was able to follow black/white target even if during the following there was an increase in pendular movements (nystagmus). Her visual acuity was low for age (Teller: $1.3 \mathrm{cy} / \mathrm{cm}$ i.e. 1.3 $\log$ MAR). She had no motor problems even if her movements were rather abrupt.

\section{6 months}

At 6 months the infant still showed a significant horizontal nystagmus, but she was able to follow a colour target over a large arc and she also began to perform vertical movements. She still had no null position for nystagmus and even if her visual acuity (measured by means of Teller acuity cards technique) improved it was still low for age (3.2 cy/cm i.e. $0.87 \operatorname{logMAR}$ ). Brain MRI was completely normal except for a cyst in a left temporal position.

\section{2 months}

The last examination revealed that the horizontal nystagmus was still present but she began to find null positions by deviating her eyes rightwards or downwards. Her visual acuity improved further and was only slightly lower than controls $(9.8 \mathrm{cy} / \mathrm{cm}$ i.e. $0.47 \log$ MAR). Her distance attention progressed to a range of one metre. She was able to sit unassisted, crawl and, with help, stand. She pronounced her first words like "mum" and "dad" and had good cognitive development.

\section{Case 2}

A second pregnancy female infant born at 40 weeks gestational age (the first was a miscarriage). The mother was administered methadone during the entire pregnancy at a dosage of $35 \mathrm{mg} /$ die whereas she denied use of other types of drugs. She used opiates and cocaine till 2 years before. The mother also referred that urine samples were collected once a week and analyzed for methadone, opiate, benzodiazepines, amphetamines, cannabinoids and cocaine metabolites and were always in the normal range. The use of alcohol, tobacco or other types of substances during pregnancy was also denied.

Other information about the mother were not available for her lack of cooperation. At birth NAS was present and treated with phenobarbital for 15 days. Starting from the first weeks a difficulty in the visual following was noticed, especially in the right hemifield.

\section{5 months}

Parents noticed abnormal ocular movements and nystagmus often associated with frequent abnormal movements involving all four limbs (similar to startle). The child was then hospitalized and examinations were performed. EEG, cranial ultrasound and ophthalmological evaluation were all within normal range. Flash VEPs were normal except for increase latency and low amplitude in right eye of non-specific significance. Brain 
MRI showed a venous angioma near the lateral portion of the left ventricle not correlated with the ocular disorder. The neurological development was normal for age.

The visual function examination revealed a pendular horizontal nystagmus with fixation that worsened when the child moved her eyes towards the right hemifield. Visual following was difficult with repeated loss of target. Horizontal saccades were present while vertical saccades were difficult because when the child tried to follow a vertically moving target nystamus increased and a rotative component was also noted. The visual acuity was low for her age $(3,2 \mathrm{cy} / \mathrm{cm}$ i.e. $0.87 \log M A R)$. No reductions in the visual field were found.

\section{8 months}

An improvement of visual function was observed. The infant still showed horizontal pendular nystagmus but less invalidating. She was able to follow a target over a large arc also vertically. Visual acuity was still low for her age $(9,8 \mathrm{cy} / \mathrm{cm}$ i.e. $0.47 \log$ MAR) but improved. Neurological development was normal.

\section{Conclusion}

There are only a few studies in literature that question the existence of a relationship between congenital nystagmus and methadone during pregnancy and, to our knowledge, this is the first description for the Italian population. In the first case the infant did not show NAS but an additional risk factor was the use of diazepam during pregnancy that, as in other benzodiazepines, can increase the risk of nystagmus [10,20]. In the second case, instead, the infant showed NAS that is often associated with nystagmus [12]. During the first examination the infants showed different characteristics but, in both cases, there was a progressive improvement of the ocular disorder, a persistent pendular horizontal nystagmus and almost normal range visual acuity.

These two cases and other studies recently published on this topic suggest paying careful attention to prenatal history of children born with congenital nystagmus in absence of other etiopathogenesis factors. Particular regard must be focused on substances and drugs that mothers could have taken during pregnancy, the dosages and frequencies. The observed differences among subjects might be due to differences in dosage or to different combinations of substances and/or drugs. When confronted with infants with congenital nystagmus, a medical history regarding pregnancy, use of substances or drugs, dosages and the start, duration and stop of drug use should be carefully investigated.

\section{Consent}

"Written informed consent was obtained from the patient for publication of this Case report and any accompanying images. A copy of the written consent is available for review by the Editor of this journal".

\section{Abbreviations}

NAS: Neonatal abstinence syndrome; EEG: Electroencephalogram; VEP: Visual evoked potential; MRI: Magnetic resonance imaging.

\section{Competing interests}

The authors declare that they have no competing interests.

\section{Authors' contributions}

FT and AG conceived the study and drafted the manuscript. FT evaluated all the two children. RB contributed to data acquisition and drafting of the article. GC contributed to data interpretation, to critical revision of the article and to final approval of the version to be published. All authors read and approved the final manuscript.

\section{Acknowledgments}

This work was supported by PRIN 2009 from the Italian Ministry of University to Giovanni Cioni.

\section{Author details}

${ }^{1}$ Department of Developmental Neuroscience, IRCCS Fondazione Stella Maris, Via dei Giacinti 2, Calambrone, Pisa 56128, Italy. ${ }^{2}$ Department of Clinical and Experimental Medicine, University of Pisa, Pisa, Italy.

Received: 10 April 2013 Accepted: 28 June 2013

Published: 3 July 2013

\section{References}

1. Farid WO, Dunlop SA, Tait RJ, Hulse GK: The effects of maternally administered methadone, buprenorphine and naltrexone on offspring: review of human and animal data. Curr Neuropharmacol 2008, 6(2):125-150.

2. Brown HL, Britton KA, Mahaffey D, Brizendine E, Hiett AK, Turnquest MA: Methadone maintenance in pregnancy: a reappraisal. Am J Obstet Gynecol 1998, 179(2):459-463.

3. Doberczak TM, Thornton JC, Bernstein J, Kandall SR: Impact of maternal drug dependency on birth weight and head circumference of offspring. Am J Dis Child 1987, 141(11):1163-1167.

4. Connaughton JF, Reeser D, Schut J, Finnegan LP: Perinatal addiction: outcome and management. Am J Obstet Gynecol 1977, 129(6):679-686.

5. Hulse GK, Milne E, English DR, Holman CD: Assessing the relationship between maternal opiate use and neonatal mortality. Addiction 1998, 93(7):1033-1042

6. Kandall SR, Albin S, Gartner LM, Lee KS, Eidelman A, Lowinson J: The narcotic-dependent mother: fetal and neonatal consequences. Early Hum Dev 1977, 1(2):159-169.

7. Arlettaz R, Kashiwagi M, Das-Kundu S, Fauchere JC, Lang A, Bucher HU: Methadone maintenance program in pregnancy in a Swiss perinatal center (II): neonatal outcome and social resources. Acta Obstet Gynecol Scand 2005, 84(2):145-150.

8. Dashe JS, Sheffield JS, Olscher DA, Todd SJ, Jackson GL, Wendel GD: Relationship between maternal methadone dosage and neonatal withdrawal. Obstet Gynecol 2002, 100(6):1244-1249.

9. Ebner N, Rohrmeister K, Winklbaur B, Baewert A, Jagsch R, Peternell A, Thau K, Fischer G: Management of neonatal abstinence syndrome in neonates born to opioid maintained women. Drug Alcohol Depend 2007, 87(2-3):131-138

10. Rottach KG, Wohlgemuth WA, Dzaja AE, Eggert T, Straube A: Effects of intravenous opioids on eye movements in humans: possible mechanisms. J Neuro/ 2002, 249(9):1200-1205

11. Whitham JN, Spurrier NJ, Sawyer MG, Baghurst PA, Taplin JE, White JM, Gordon AL: The effects of prenatal exposure to buprenorphine or methadone on infant visual evoked potentials. Neurotoxicol Teratol 2010, 32(2):280-288.

12. Hamilton R, McGlone L, MacKinnon JR, Russell HC, Bradnam MS, Mactier H: Ophthalmic, clinical and visual electrophysiological findings in children born to mothers prescribed substitute methadone in pregnancy. Br J Ophthalmol 2010, 94(6):696-700. 
13. Gupta M, Mulvihill AO, Lascaratos G, Fleck BW, George ND: Nystagmus and reduced visual acuity secondary to drug exposure In utero: long-term follow-up. J Pediatr Ophthalmol Strabismus 2012, 49(1):58-63.

14. Mulvihill AO, Cackett PD, George ND, Fleck BW: Nystagmus secondary to drug exposure in utero. Br J Ophthalmol 2007, 91(5):613-615.

15. Spiteri Cornish K, Hrabovsky M, Scott NW, Myerscough E, Reddy AR: The Short- and Long-term Effects on the Visual System of Children Following Exposure to Maternal Substance Misuse in Pregnancy. Am J Ophthalmol 2013, 156(1):190-194.

16. McGlone L, Hamilton R, McCulloch DL, Boulton R, Bradnam MS, Weaver LT, Mactier H: Neonatal visual evoked potentials in infants born to mothers prescribed methadone. Pediatrics 2013, 131(3):e857-e863.

17. Cannon SC, Robinson DA: Loss of the neural integrator of the oculomotor system from brain stem lesions in monkey. J Neurophysiol 1987, 57(5):1383-1409.

18. Lin Y, Carpenter DO: Direct excitatory opiate effects mediated by nonsynaptic actions on rat medial vestibular neurons. Eur J Pharmacol 1994, 262(1-2):99-106.

19. Sulaiman MR, Dutia MB: Opioid inhibition of rat medial vestibular nucleus neurones in vitro and its dependence on age. Exp Brain Res 1998, 122(2):196-202.

20. Rothenberg SJ, Selkoe D: Specific oculomotor deficit after diazepam. II. Smooth pursuit eye movements. Psychopharmacol (Berl) 1981, 74(3):237-240.

doi:10.1186/1824-7288-39-40

Cite this article as: Tinelli et al:: Congenital nystagmus in two infants born from mothers exposed to methadone during pregnancy. Italian Journal of Pediatrics 2013 39:40.

\section{Submit your next manuscript to BioMed Central and take full advantage of:}

- Convenient online submission

- Thorough peer review

- No space constraints or color figure charges

- Immediate publication on acceptance

- Inclusion in PubMed, CAS, Scopus and Google Scholar

- Research which is freely available for redistribution 